\title{
Socioeconomic factors contributing to under-five mortality in sub-Saharan Africa: a decomposition analysis
}

\author{
Carine Van Malderen ${ }^{1 *}$, Agbessi Amouzou², Aluisio J. D. Barros ${ }^{3}$, Bruno Masquelier ${ }^{4,5}$, Herman Van Oyen ${ }^{6,7}$ and \\ Niko Speybroeck ${ }^{1}$
}

\begin{abstract}
Background: In sub-Saharan Africa, socioeconomic factors such as place of residence, mother's educational level, or household wealth, are strongly associated with risk factors of under-five mortality (U5M) such as health behavior or exposure to diseases and injuries. The aim of the study was to assess the relative contribution of four known socioeconomic factors to the variability in U5M in sub-Saharan countries.

Methods: The study was based on birth histories from the Demographic and Health Surveys conducted in 32 subSaharan countries in 2010-2016. The relative contribution of sex of the child, place of residence, mother's educational level, and household wealth to the variability in U5M was assessed using a regression-based decomposition of a Gini-type index.

Results: The Gini index - measuring the variability in U5M related to the four socioeconomic factors - varied from 0.006 (95\%Cl: 0.001-0.010) in Liberia 2013 to 0.034 (95\%Cl: 0.029-0.039) in Côte d'Ivoire 2011/12. The main contributors to the Gini index (with a relative contribution higher than 25\%) were different across countries: mother's educational level in 13 countries, sex of the child in 12 countries, household wealth in 11 countries, and place of residence in 8 countries (in some countries, more than one main contributor was identified).

Conclusions: Factors related to socioeconomic status exert varied effects on the variability in U5M in sub-Saharan African countries. The findings provide evidence in support of prioritizing intersectoral interventions aiming at improving child survival in all subgroups of a population.
\end{abstract}

Keywords: Under-five mortality, Sub-Saharan Africa, Poisson regression, Gini decomposition, Socioeconomic inequalities

\section{Background}

The under-5 mortality rate (U5MR), the probability of dying before 5 years of age (per 1000 live births), is a key global indicator of child health [1], and one of the most important measures of global health [2]. Previously targeted in the fourth Millennium Development Goal (MDG), U5MR now appears in the third Sustainable Development Goal (SDG3) [3], aiming to reduce under-5 mortality to at least as low as 25 deaths per 1000 live births in all countries by 2030. Though the global U5MR

\footnotetext{
* Correspondence: carine.vanmalderen@uclouvain.be

${ }^{1}$ Institute of Health and Society (IRSS), Université catholique de Louvain,

Brussels, Belgium

Full list of author information is available at the end of the article
}

dropped from 93 deaths per 1000 live births in 1990 to 39 in 2017, the highest rates are still seen in sub-Saharan Africa, with an U5MR of 76 deaths per 1000 live births in 2017, leading to 2.7 million deaths in the region. A vast majority of these deaths are amenable to health care and prevention, as the leading causes of death among children under age five include preterm birth complications, pneumonia, intrapartum-related complications, diarrhea and malaria $[4,5]$.

Even if U5MR has declined in most sub-Saharan African countries, substantial inequalities between subgroups of the population still exist within countries [6]. Population sub-groups may be defined by different dimensions such as place of residence, sex of children,

(c) The Author(s). 2019 Open Access This article is distributed under the terms of the Creative Commons Attribution 4.0 International License (http://creativecommons.org/licenses/by/4.0/), which permits unrestricted use, distribution, and 
ethnicity, and maternal factors such as educational level, occupation or income [7]. These socioeconomic factors are included in the Mosley and Chen conceptual framework as the distal determinants of child mortality [7]. In this framework, socioeconomic determinants operate at three levels (the community, the household, and the individual) and affect mortality through proximate determinants such as maternal factors, environmental contamination, nutrient deficiency, injury, and personal illness control.

The magnitude of socioeconomic inequalities in U5MR may be assessed by studying each socioeconomic factor separately, using the concentration index, and income or wealth are among the most widely studied [810]. However, the concentration index measuring wealth-related inequalities in U5MR was not significant in several sub-Saharan countries [8, 11], an observation calling for further research on other dimensions of socioeconomic inequalities in U5MR.

Identifying the larger socioeconomic gaps in U5MR across a population may be done by assessing the relative contribution of several socioeconomic factors to the variability in U5MR, using a multivariate regression model and additional decomposition techniques [12].

Taking a set of four socioeconomic factors representative of the multiple dimensions of a society's stratification in U5MR, the aim of the study was to identify which one(s) contributed the most to the variability in U5MR in sub-Saharan African countries.

\section{Methods}

\section{Conceptual framework}

Four factors were selected as proxies for the main socioeconomic determinants introduced by Mosley \& Chen [13]: place of residence for the community level (ecological setting, political economy and health system), household wealth for the household level (goods and services such as food, housing, transportation, financial access to care), mother's educational attainment for the individual level (mother's choices and skills in health care practices), and sex of the child also for the individual level (differential feeding and medical care practices). However, the gender of the child may represent both gender discrimination and a biological disadvantage [14]. These four factors are the main socioeconomic factors used to describe U5MR by population subgroups at the international level $[6,10,14,15]$.

\section{Data}

Data from 32 Sub-Saharan African countries with a standard Demographic and Health Survey (DHS) completed in 2010-2016 (the most recent available at the time of the analysis, in July 2018) were used. Details on survey sampling, data collection and data processing are available on the DHS Program website [16]. In total, the study gathered data from 366,960 children obtained from the interview of 248,732 mothers.

The outcome variable was under-five death. This information was obtained from the birth history of interviewed females aged 15 to 49 [16]. The analysis was restricted to the last 5 years preceding the survey to limit the time gap between the event and the collection of socioeconomic information. The socioeconomic factors investigated were: sex of the child, place of residence (urban or rural), mother's educational level (lower than primary, primary and above), and household wealth (poorest/middle tertiles versus the highest tertile). Household wealth tertiles were derived from the wealth index provided with the DHS data, constructed from several household assets (type of flooring, water supply, sanitation facilities, electricity, persons per sleeping room, ownership of agricultural land, domestic servant, and other assets). U5MR was calculated in each wealth tertile, then the tertiles "poorest" and "middle", showing similar levels of U5MR in a majority of countries, were pooled to have the same number of categories for the four variables, hence avoiding any bias overestimating the contribution of variables with more categories. The proportion of missing values for the included variables was lower than $0.03 \%$ in all countries.

\section{Data analysis}

Distinct individual level analyses were carried out for the 32 included countries. U5MR was estimated in each population sub-group with the synthetic cohort probability method employed in DHS [17]. Differences in U5MR between subgroups were tested with a bootstrap technique.

The relative contribution of each factor to the variability in U5MR was made using a regression-based decomposition of a Gini index, described below.

A multivariate Poisson regression model (with exposure time as offset) was used. Multi-collinearity was checked and no variance inflation factor was greater than 10. Analyses were weighted (using weights available in the DHS datasets), accounting for clustering (with cluster as the primary sampling unit and household as the secondary sampling unit) and for stratification (with region as strata). The significance threshold was set up at $5 \%$.

Variability in the obtained individuals' predicted death rates was assessed with a Gini index (G), and decomposed using Wagstaff's method [18-21]. G is defined as twice the covariance of the health variable (here predicted death rates) and the person's fractional rank in the distribution of health, divided by the mean level of health. As the mean of the predicted death rates was negative, $G$ ranged between -1 (maximum variability) and 0 (no variability), but for the description of the variability in all countries, 
the sign was reversed so higher values mean more variability. A factor's relative contribution to the Gini index is the product of its elasticity $\left(\frac{b \bar{x}}{\bar{y}}\right.$, where $b$ is the factor's regression coefficient, $\bar{x}$ its mean and $\bar{y}$ the mean of the predicted death rates) and its concentration index (a Ginitype measure of its unequal distribution in the population ranked by predicted death rate), divided by the overall G. Factors' concentration indexes ranged from - 1 (the factor is more concentrated among the lower values of the health variable) to 1 (the factor is more concentrated among the higher values of the health variable), 0 meaning equal distribution in the population. The four factors' relative contributions were presented in percent, adding up to $100 \%$. A factor was defined as a main contributor if it contributed to at least $25 \%$ to the variability in U5M.

RGui ( $\mathrm{R}$ version 3.4.0., The $\mathrm{R}$ foundation for Statistical Computing) and Stata 14.0 (calculation of U5M) were used for the data analysis (an overview of the $\mathrm{R}$ code is provided in Appendix 1).

\section{Results}

Under-five mortality rate (U5MR) versus variability in U5MR in the 32 countries

U5MR ranged from 49 [95\%CI:42;57] deaths per 1000 live births in Rwanda 2014/15 to 152 [95\%CI:138;166] in Sierra Leone 2013 (Fig. 1). The Gini index, assessing the variability in U5MR related to the four factors - sex of the child, place of residence, mother's education and household wealth, varied from 0.006 (95\%CI: $0.001-$ 0.010 ) in Liberia 2013 to 0.034 (95\%CI: $0.029-0.039)$ in Côte d'Ivoire 2011/12. No correlation could be identified between U5MR and the Gini indexes (Pearson's correlation coefficient $\mathrm{r}=0.10, p=0.59$ ). Table 1 shows U5MR in all countries, at national level and by population subgroup. U5MR was significantly lower in females compared to males in 9 countries, in urban compared to rural areas in 12 countries (the contrary was observed in Tanzania 2015/16 where U5MR was higher in urban areas), in children born to mothers with at least a primary education compared to children born to mothers without any formal education in 19 countries, and in the richest households compared to the poorest of middle wealth households in 17 countries.

\section{Factors associated with U5MR in the multivariate analyses, and their relative contribution to the variability in U5MR}

Table 2 shows all components of the Gini index decomposition: the overall Gini index, the mean of the predicted death rates (obtained with the multivariate Poisson regression model), variables' means, regression coefficients, and concentration indexes. The relative contribution of a factor is calculated as the product of its mean, its regression coefficient, and its concentration index, divided by the mean of the predicted death rates, then by the overall Gini index. For instance, the relative contribution of sex of the child in the 20112012 DHS in Benin equals 0.48*(-0.20)*(-0.29) / $6.34 /-0.017=26 \%$. In Fig. 2 , countries were classified according to the factor(s) which contributed to more than $25 \%$ of the variability in U5M. As the relative contributions add up to $100 \%$ and we consider 4 different factors, a contribution exceeding $25 \%$ for one factor suggests the existence of a socioeconomic gap in U5MR more marked than for the other factors.

\section{Sex of the child}

After adjustment for the three other covariates, the U5MR was significantly lower in girls than in boys in 16 countries (Table 2). Among the 12 countries where sex of the child contributed to more than $25 \%$ of the variability in U5MR, this factor was the only main contributor in Chad 2014/15, Côte d'Ivoire 2011/12, Ethiopia 2016, Gabon 2012, Malawi 2015/16, and Sierra Leone 2013 (Fig. 2).

\section{Place of residence}

The proportion of children living in urban areas varied from 9\% in Burundi 2016/17 to 84\% in Gabon 2012. After adjustment, the excess rural mortality was significant in Niger 2012, Nigeria 2013, Senegal 2010/11, and Comoros 2012, and the excess urban mortality was significant in Kenya 2014 and Tanzania 2015/16 (Table 2). Among the 8 countries where place of residence contributed to more than $25 \%$ of the variability in U5MR, this factor was the only main contributor in Kenya 2014, Niger 2012, Senegal 2010/11, Tanzania 2015/16, and Namibia 2013 (Fig. 2).

\section{Mother's education}

The proportion of children whose mother had at least a primary education level varied from 6\% in Niger 2012 to $86 \%$ in Zimbabwe 2015. After adjustment, the observed protective effect of mother's education on U5MR was significant in Gambia 2013, Nigeria 2013, Togo 2013/14, Cameroon 2011, and Uganda 2016. Among the 12 countries where mother's education contributed to more than $25 \%$ of the variability in U5MR, this factor was the only main contributor in Ghana 2014, Gambia 2013, Liberia 2013, and Togo 2013/14, four countries in Western Africa (Fig. 2).

\section{Household wealth}

After adjustment, the observed protective effect of household wealth on U5M was significant in 10 countries. Among the 11 countries where household wealth 


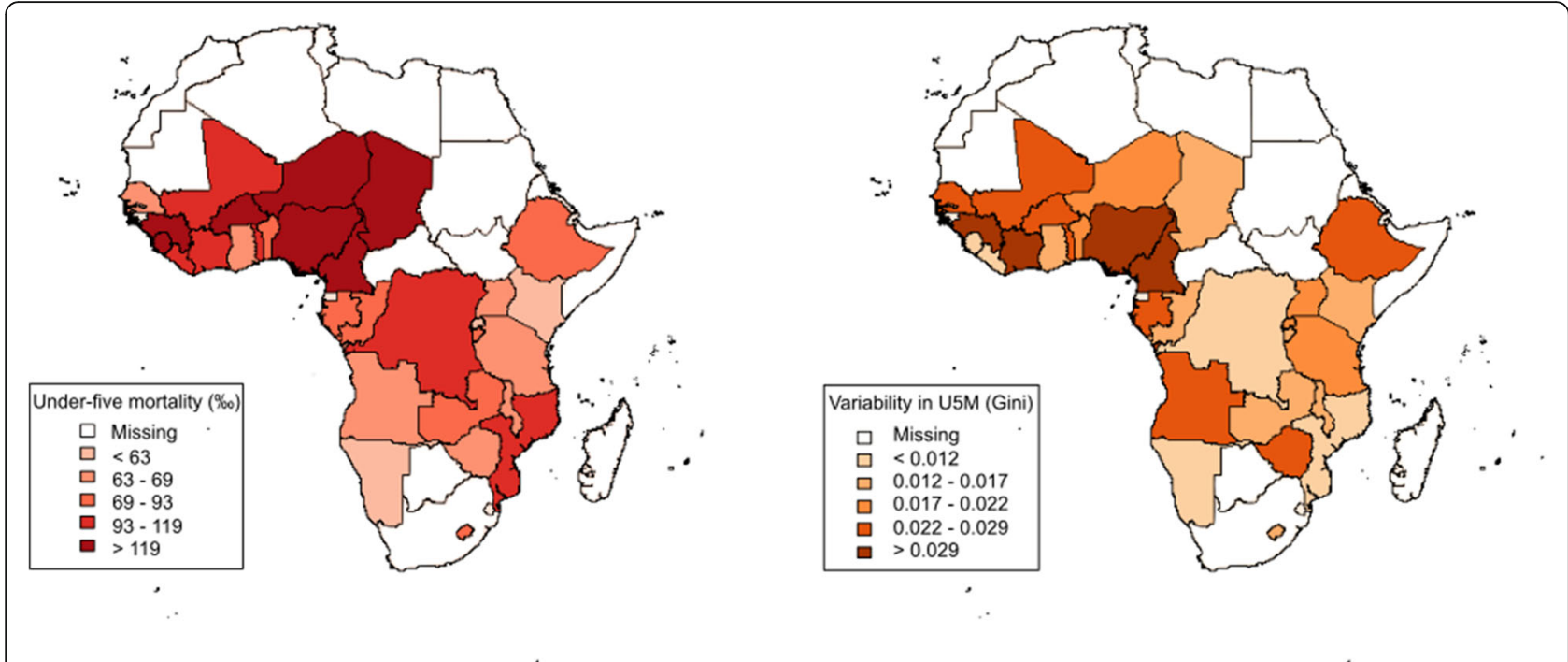

Fig. 1 Under-five mortality rates (U5MR, left) versus variability in U5MR measured by a Gini index (right) in the 32 countries, Demographic and Health Surveys 2010-2016 (0-5 years prior to each survey)

contributed to more than $25 \%$ of the variability in U5MR, this factor was the only main contributor in Angola 2015/16, Burkina Faso 2010, DR Congo 2013/ 14, Guinea 2012, Mali 2012/13, and Zimbabwe 2015 (Fig. 2).

\section{Combination of socioeconomic factors}

In some countries, more than one factor contributed to more than $25 \%$ of the variability in U5MR: sex of the child and mother's education in Mozambique 2011, Uganda 2016, Zambia 2013/14, and Rwanda 2014/15; sex of the child and household wealth in Benin 2011/ 12, sex of the child and place of residence in Congo 2011/12; mother's education and household wealth in Burundi 2016/17 and Nigeria 2013, household wealth and place of residence in Namibia 2013, mother's education and place of residence in Comoros 2012 and Lesotho 2014, and sex of the child, mother's education, and household wealth in Rwanda 2014/15.

\section{Discussion}

\section{Main results}

This study shows that major inequalities in U5MR still exist in sub-Saharan Africa in 2010-2016 but that there is not just one single story applicable to all countries. The relative contribution of four socioeconomic factors to the variability in U5MR was assessed using a regression-based decomposition of a Gini index.

The main contributors differed according to the country.

In Benin, Chad, Congo, Côte d'Ivoire, Ethiopia, Gabon, Malawi, Mozambique, Rwanda, Sierra Leone, Uganda, and Zambia, considerable inequalities between boys and girls were observed. It has been shown that differences in survival between boys and girls exist at least up to the age of 5 years [14]. An excess male child mortality can be explained by biological factors (lower resistance to infection, higher risk of premature birth, difficult labour related to a larger average body size and head circumference), gender discrimination (differential feeding and medical care practices, or response to HIV-related drugs) [22, 23]. After adjusting for a range of individual, household and community variables (including age, birth order, household wealth, maternal education but also skilled birth attendance and other factors), the excess male mortality remained significant in several countries in Sub-Saharan Africa [24].

In Comoros, Congo, Kenya, Lesotho, Namibia, Niger, Senegal, and Tanzania, considerable inequalities related to the place of residence were observed in this analysis. In Comoros, Lesotho, Namibia, Niger, and Senegal, U5MR was lower in urban areas while in Congo, Kenya, and Tanzania, U5MR was lower in rural areas. The effect of place of residence on U5MR, adjusted for sex of the child, mother's education, and household wealth, may have operated through ecological setting, political economy and health system $[13,25]$. Though the urban-rural difference is narrowing or even reversing in some countries (as a result of a more rapid mortality decline in rural areas than in urban areas and deplorable living conditions in urban slums [26]), an urban advantage persists in many countries. This urban advantage can be attributed to access to health services and better economic opportunities for families [27, 28]. 


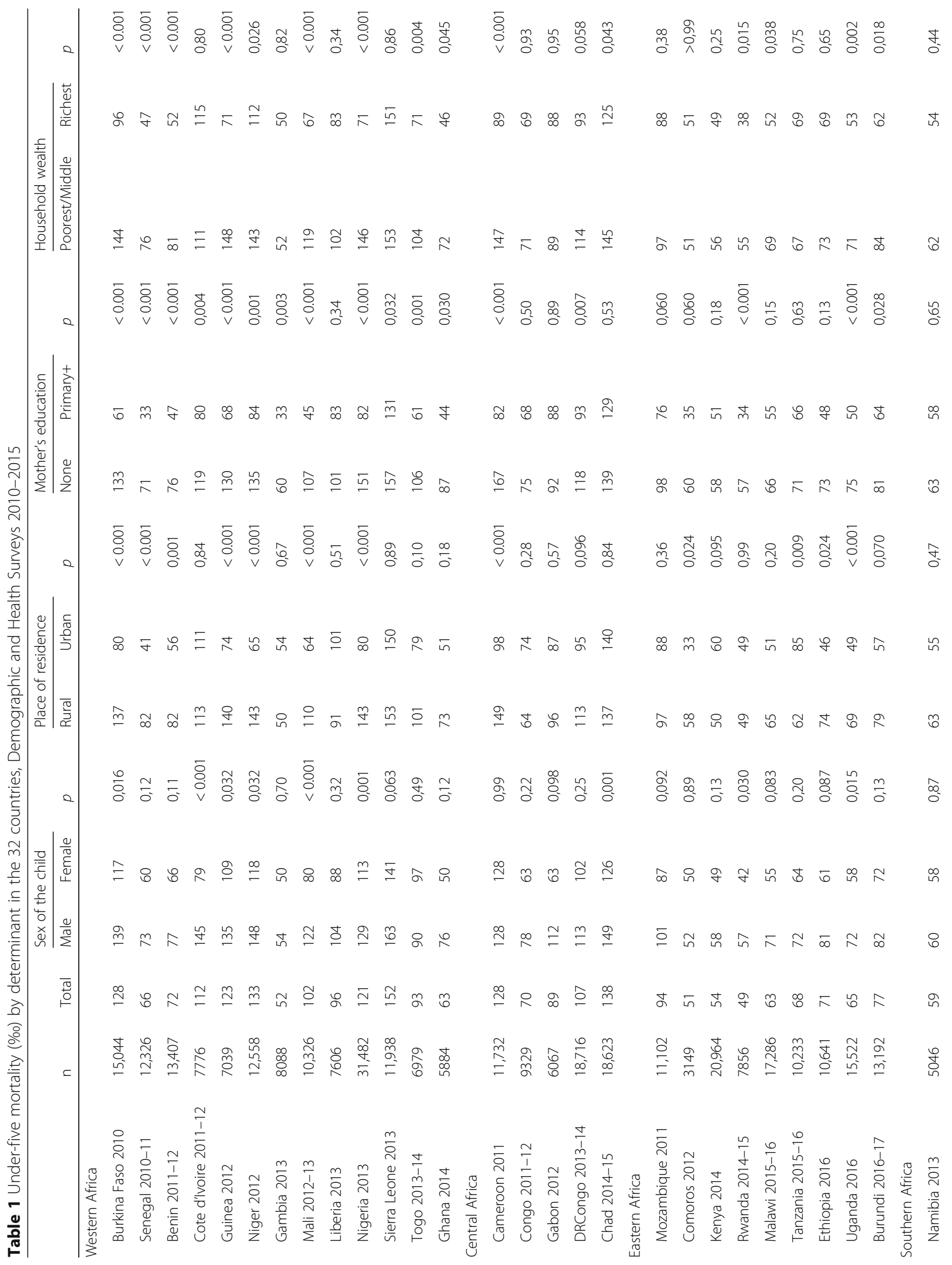




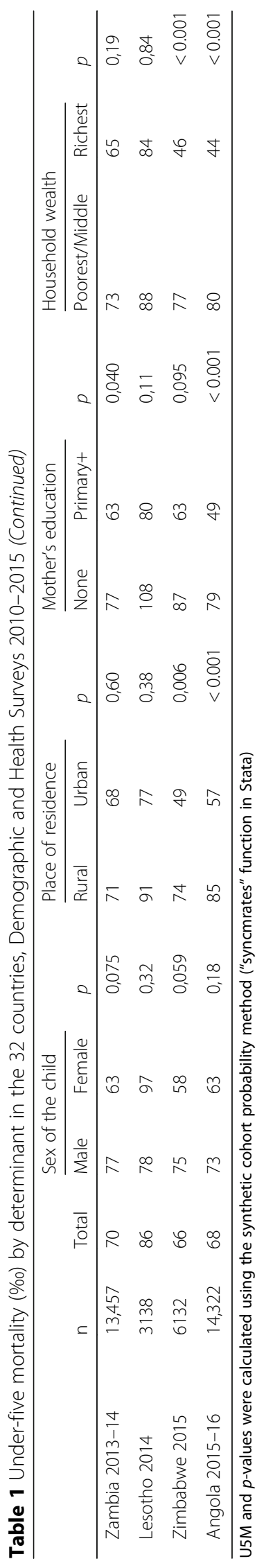




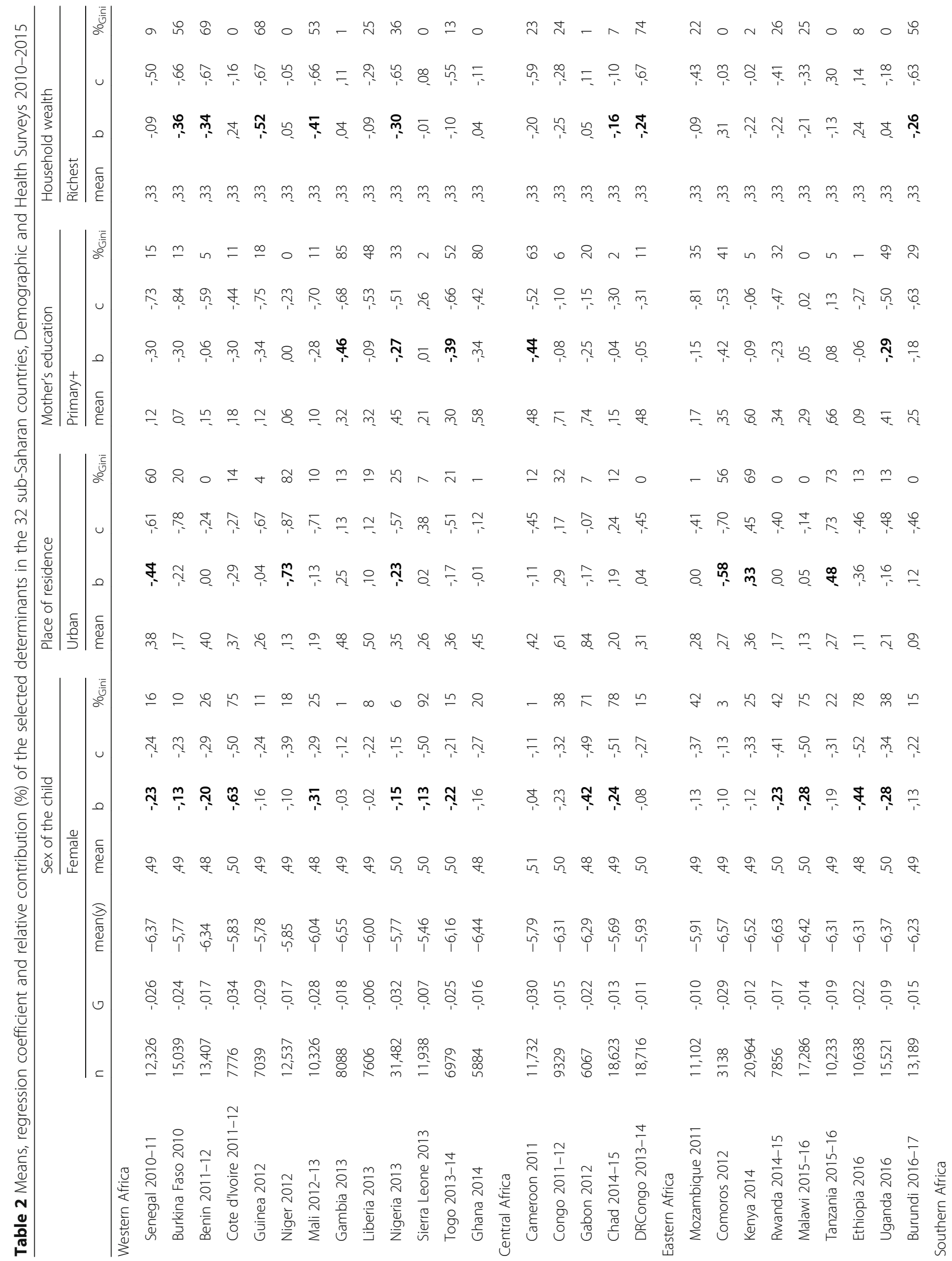




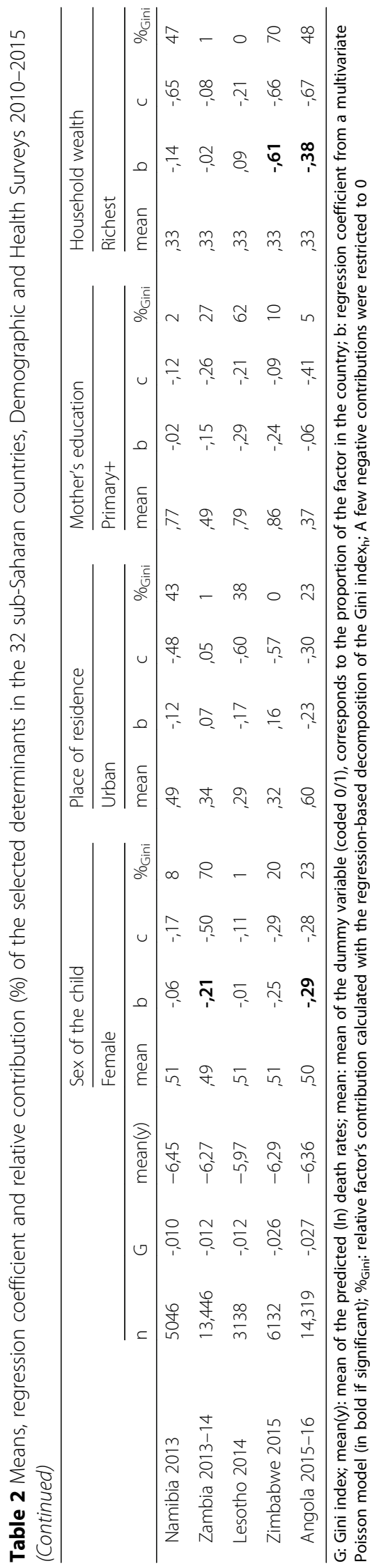




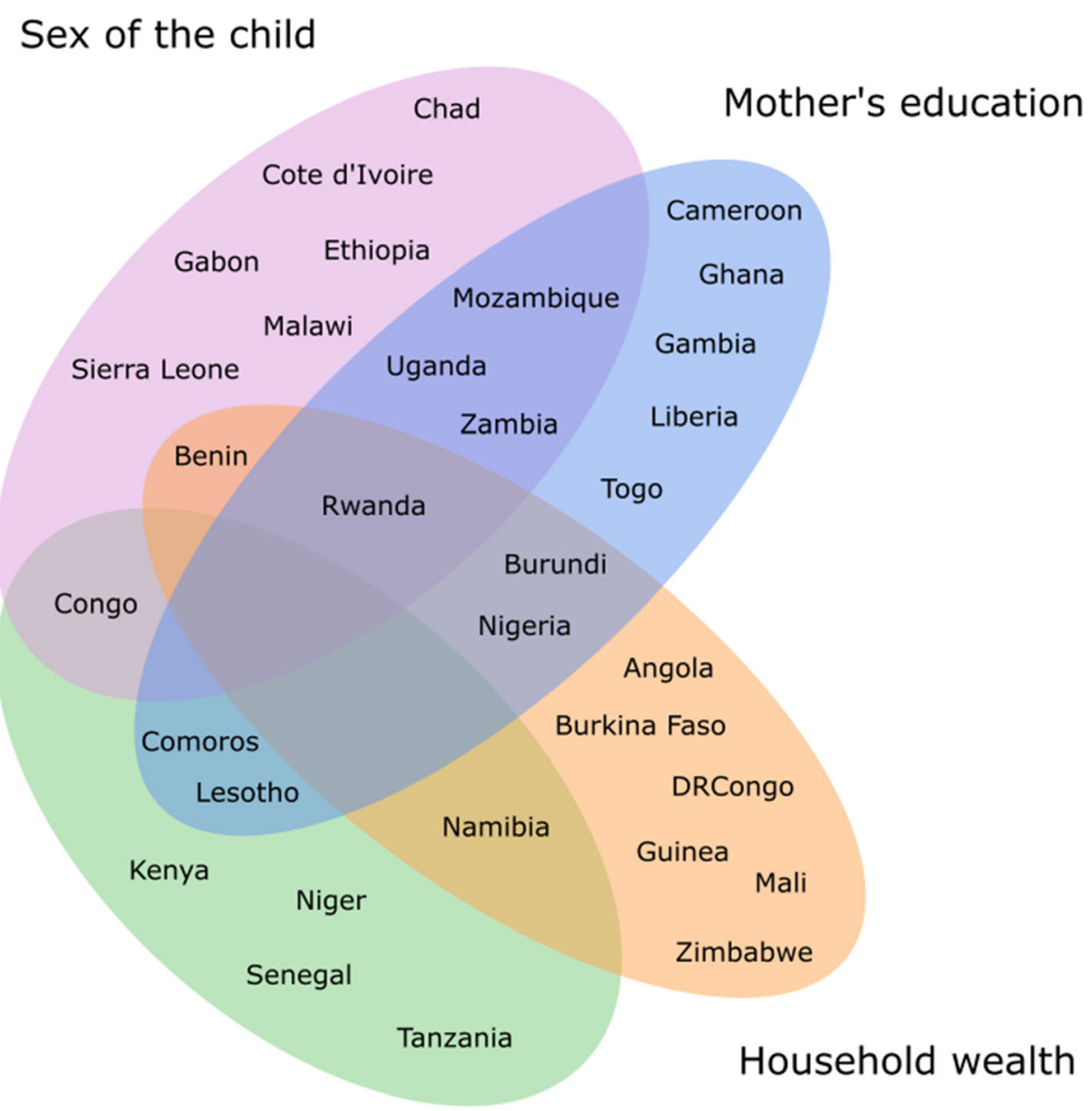

\section{Place of residence}

Fig. 2 Classification of the 32 countries according to the main contributors to the variability in U5MR. A factor was defined as a main contributor if its contribution to the variability in U5MR exceeded 25\% according to the regression-based decomposition of the Gini index (Table 2). The Venn diagram was developed using the R function "venn.diagram"

In Niger, the observed excess infant mortality, was partly explained by the existence of a health facility within the community [29].

In Burundi, Cameroon, Comoros, Gambia, Ghana, Lesotho, Liberia, Mozambique, Nigeria, Rwanda, Uganda, and Zambia, considerable inequalities related to the mother's educational level were observed, with lower mortality rates if the mother had at least a primary educational level. The effect of mother's education on U5MR, adjusted for sex of the child, place of residence, and household wealth, may have operated through empowerment, health and reproductive behaviour (e.g. birth spacing) or health services utilization (e.g. knowledge, awareness) [13, 25]. This protective effect of maternal education adjusted for more covariates than in the study at hand, was also reported in Ghana [30], and Comoros [31]. Some assumptions suggested in a study on the factors associated with
U5MR in rural Ghana were: educated mothers are more likely to receive antenatal care [32] (though the gap seems to be closing over time [33]), and motherhood could be delayed, decreasing the total number of children [34]. A recent study including, among other countries, Ghana and Nigeria showed that women's education was associated with utilization of maternal health services: type of antenatal care provider, timing and frequency of antenatal care visits, place of delivery and presence of a skilled birth attendant at delivery [35]. Another study including Cameroon and Niger (among other countries), highlighted that the decline in under-five mortality rates, during last two decades, can be partly due to the government policies on women's education, resulting in increased maternal awareness about child health and hygiene [36].

In Angola, Benin, Burundi, Burkina Faso, DR Congo, Guinea, Mali, Namibia, Nigeria, Rwanda, and Zimbabwe, 
considerable inequalities related to the household wealth were observed, with lower mortality rates in richest households. The effect of household wealth on U5MR, adjusted for sex of the child, place of residence, and mother's educational level, may have operated through access to goods and services such as food, housing, transportation, or financial access to care [13, 25]. A study looking at changes in inequalities between the poorest and the least poor in mortality levels, using comparisons between successive surveys, showed that these inequalities widened in some of the aforementioned countries: Benin (2001), Namibia (2000) [37], Burundi (2010), Burkina Faso (2010), DR Congo (2007), Mali (2010), Nigeria (2008), and Rwanda (2010) [38].

The current paper focuses on U5MR but a subanalysis by age group was also conducted (see Appendix 2), distinguishing between neonatal mortality (0-1 month), post-neonatal mortality (1-11 months), infant mortality (0-11 months) and child mortality (12-59 months). This analysis showed that the main sources of inequality vary according to the age group: household wealth and sex of the child for neonatal mortality, mother's education and sex of the child for infant mortality, mother's education, household wealth and place of residence for post-neonatal and child mortality. This is in line with previous literature showing changes in the sex ratios of mortality as children get older [14], and suggests that later in the life of children, the socioeconomic factors such as household wealth, mother's education and place of residence, may become more important sources of inequalities between subgroups. We report here mainly on under- 5 mortality, because it is one of the indicators recommended by the World Health Organization for policy-oriented monitoring of equity ("Under-5 mortality and, where possible, its components assessed separately: neonatal, neonatal, postneonatal, and infant mortality, and mortality among children 1-4 years") [39]. The small number of deaths in the subgroup 1-4 years made the analysis less reliable. Further analysis should also consider children aged between 5 and 14 years, because about 1 million die globally in this age group [40], but there is very limited research on socioeconomic factors of child mortality beyond age 5 .

\section{Limitations}

The DHS program provide quality survey data, both through internal quality assurance and control procedures (continuous instrument quality checks, appropriate field personnel training, high response rate [41] and through its transparent data files and survey methods descriptions [42]. However, the cross-sectional design of the survey does not allow accounting for the order of events; information on mother or household characteristics at the time of the interview does not fully reflect the status at child death. Information on child death depends on the mother's will and ability to communicate the information, and reporting quality may vary across social groups [6]. Moreover, the U5MR estimates based on birth histories may differ from estimates based on vital registration systems, due to recall errors in reporting vital events or ages of children at death or at survey [43]. In addition, due to relatively small sample sizes, some categories have to been pooled together. In this study, mother's education "secondary or higher" was pooled with primary education because too few cases were present in the former category, resulting in aberrant estimates. This type of transformation is likely to reduce the explanatory power of this variable. Similarly, household wealth tertile was dichotomized to avoid overestimating its contribution. In Sierra Leone, the middle wealth tertile showed the highest U5MR while in Comoros, the middle wealth tertile showed the lowest U5MR, but these differences were not significant. These effects were not shown in the analyses presented above and focusing on a difference between the richest and the others. Finally, it should be kept in mind that the four factors are hierarchically related [44] and the effect of place of residence may have been mediated by mother's education or household wealth, thereby underestimating its relative contribution.

The study focuses on four known socioeconomic factors, but some external factors, such as conflicts, with potentially large impact on child mortality and socioeconomic resources in a country, were not adjusted for. A study matching birth histories from Demographic and Health Surveys with data on proximity to armed conflict (reported in the Uppsala Conflict Data Program Georeferenced Events Dataset) showed that the risk of dying before reaching age 1 was $5 \cdot 2$ per 1000 births higher for a child born within $50 \mathrm{~km}$ of an armed conflict than for a child born in the same region during periods without conflict (corresponding to a $7.7 \%$ increase above baseline) [45]. Among the 32 countries included in this study, 11 countries were affected by an armed conflict during the survey or in the five preceding years. The most affected countries were DR Congo (6617 armed-related deaths during the defined period), Nigeria (3169 deaths), and Mali (1349 deaths) [46]. However, studying how the socioeconomic factors contributing to under-five mortality in Sub-Saharan Africa change in conflict-affected settings is beyond the scope of this paper. More broadly, any positive or negative change in the organization or resources of a country or a community (health insurance, epidemics, pollution, migration or fertility) is likely to impact the distribution 
of the socioeconomic resources and their combined effect on child health.

\section{Perspectives}

First, the study focuses on relative inequality in U5MR between subgroups of the population. Considering absolute differences between groups is as important [47] because a low relative difference may hide a high absolute difference in high-mortality countries. The use of multivariate additive hazard models, also combining the prevalence and impact of the factors, $[48,49]$ could allow balancing the importance in absolute differences of each factor controlling for others, with a possibility to consider the "background" contribution of the factors not included.

Second, the identification of the main socioeconomic contributors to the variability in U5MR among the four factors deserve more investigations. To this end, other known factors associated with U5MR (such as antenatal care, skilled attendance at birth, access to sanitation facilities, age of the mother at birth, parity, region etc.) could be added in the multivariate models in order to explain the observed differences (but in DHS, some of these factors are known only for the surviving children). In addition, if a wealth-related inequality in U5MR is concerning, a regression-based decomposition of the concentration index could be performed, as was done before [11].

Third, another way forward would be to assess the association between changes in the socioeconomic factors and changes in U5MR over time, as Demographic and Health surveys, are being conducted every 5 years and allow exploring the impact of possible changes in the socioeconomic resources induced by major policies or crises in a country.

Fourth, although we found no significant correlation between U5MR and the Gini index related to sex of the child, place of residence, mother's education or household wealth, this observation does not exclude a correlation with the Gini index commonly used to measure income-related inequality in a country [46]. Possible correlations between indicators such as U5MR, the "traditional Gini Index", "Gross Domestic Product", and other country-level indicators could be done using the data provided with the World Bank. Such an ecological (country-level) study was conducted on under-five mortality trends in sub-Saharan Africa between 1960 and 2000 and showed that U5MR was negatively associated with per capita income and urbanization, and positively associated with illiteracy [50]. Another study showed that the decline in U5MR was associated with several Worldwide Governance Indicators: government effectiveness, rule of law, control of corruption, regulatory quality, political stability and absence of violence [38].
Finally, in this study, the independent effect of the four socioeconomic factors on U5MR determined their contributions to the variability in U5MR. However, these factors may have interacting effects and the major differences could be between subgroups defined by several dimensions (e.g. girls from richest households living in urban areas vs boys from poorest households living in rural areas). A more in-depth detection of inequalities could be studied by including interaction terms into the regression models, or by using tools handling unspecified complex interactions such as classification and regression trees [51] and random forest [52].

\section{Conclusions}

Socioeconomic inequalities in U5MR exist in all countries, but the socioeconomic dimensions may differ across countries. Identifying these main contributors is important to guide research and interventions aiming at reducing U5MR in all population subgroups. Mother's educational level appeared as an important factor in a majority of countries, followed by sex of the child, household wealth, and place of residence.

\section{Appendix 1}

\section{Overview of the $\mathrm{R}$ code used}

\# packages requiredlibrary(survey);library(foreign);library(car); library(party) ; library(decomp) ; library(VennDiagram)\# import data and specify the survey designBenin<-read.dta("Benin.dta")Beninc $<$-svydesign(id=as.formula(" $\sim$ PSU+household"), weight=as.formula(" weights"), strata=as.formula (" $\sim$ region"),data=Benin)\# Poisson regression-based decomposition methodm<-svyglm(deadu5 female+rural+ed+richest,offset= $\log ($ time),Beninc, family="quasipoisson") $p r<-$ as. numeric $($ predict $(\mathrm{m}, \quad$ newdata $=\operatorname{m\$ model}[,-1], \mathrm{vcov}=$ FALSE))Benin\$pr<-prc<-contribution(m,Benin\$pr)\# Venneuler (csv file one column by determinant coded $1 / 0 \mathrm{im}$ portant or not)d<-read.csv("Imp.csv", sep=";", header=T) venn.diagram $(\mathrm{x}=\operatorname{list}(\operatorname{Sex}=\operatorname{which}(\mathrm{d}[, 1]==1)$, Residence $=$ which $(\mathrm{d}[, 2]==1)$,Education = which $(\mathrm{d}[, 3]==1)$, Wealth = which $(\mathrm{d}[, 4]==1)$ ),imagetype = "svg",fill = c("plum", "palegreen3", "cornflowerblue", "tan1"), filename="venn.svg");\# Figure 1 map, example for U5Mlibrary(maptools) ; library(sp) ; library(lattice) ; library(shapefiles)library(RColorBrewer) ; library(classInt)shp<-readShapePoly("AfricanCountires")shp= merge(shp,result,by='COUNTRY', all. $x=T$, duplicateGeoms= T)quantile(shp\$U5M[shp\$U5M $>0]$, probs $=(0: 5) / 5)$ brks $<-$ classIntervals(shp\$U5M,n=5,style="fixed", fixedBreaks $=\mathrm{c}(0$, 49,63,68.8,93,119.2,152))cols<-brewer.pal(6, "Reds")plot(shp, col=cols[findInterval(shp\$U5M, brks\$brks, all.inside=T)]) legend("bottomleft", legend=leglabs(round(brks\$brks,1), under $="<"$, over $=">$ ", between $="-")$, fill $=$ cols, title $=$ "Underfive mortality $(\%) "$, inset $=.12$, cex $=0.8$ ) 


\section{Appendix 2}

\section{Analysis by age group}

Table 3 Neonatal mortality (0-1 month)

\begin{tabular}{|c|c|c|c|c|c|c|c|c|c|c|c|c|c|c|c|c|c|c|c|}
\hline & \multirow[b]{3}{*}{$\mathrm{n}$} & \multirow[b]{3}{*}{ G } & \multirow[b]{3}{*}{ mean $(y)$} & \multicolumn{4}{|c|}{ Sex of the child } & \multicolumn{4}{|c|}{ Place of residence } & \multicolumn{4}{|c|}{ Mother's education } & \multicolumn{4}{|c|}{ Household wealth } \\
\hline & & & & \multicolumn{4}{|c|}{ Female } & \multicolumn{4}{|l|}{ Urban } & \multicolumn{4}{|c|}{ Primary+ } & \multicolumn{4}{|l|}{ Richest } \\
\hline & & & & mean & $b$ & c & $\%_{\text {Gini }}$ & mean & $\mathrm{b}$ & c & $\%_{\text {Gini }}$ & mean & $\mathrm{b}$ & c & $\%_{\text {Gini }}$ & mean & $\mathrm{b}$ & c & $\%_{\text {Gin }}$ \\
\hline Angola 2015-16 & 445 & -.213 & -.32 & .41 & -.15 & -.45 & 40 & .51 & .01 & -.07 & 0 & .31 & .12 & .07 & 4 & .29 & -.26 & -.51 & 56 \\
\hline Benin 2011-12 & 406 & -.065 & -.28 & .43 & .01 & .22 & 6 & .43 & .00 & -.05 & 0 & .13 & .12 & .87 & 73 & .34 & -.03 & -.35 & 21 \\
\hline Burkina Faso 2010 & 560 & -.102 & -.29 & .44 & .03 & .32 & 13 & .15 & -.07 & -.76 & 25 & .06 & .08 & -.17 & 0 & .29 & -.09 & -.69 & 62 \\
\hline Burundi 2016-17 & 395 & -.121 & -.31 & .46 & -.07 & -.33 & 29 & .12 & -.05 & .04 & 0 & .26 & -.09 & -.36 & 23 & .34 & .12 & .44 & 48 \\
\hline Cameroon 2011 & 434 & -.090 & -.22 & .49 & -.03 & -.21 & 14 & .38 & -.02 & .38 & 0 & .44 & .03 & .48 & 32 & .29 & .06 & .69 & 55 \\
\hline Chad 2014-15 & 712 & -.192 & -.24 & .44 & -.10 & -.42 & 42 & .20 & -.13 & -.02 & 1 & .16 & -.09 & -.39 & 12 & .31 & .17 & .38 & 45 \\
\hline Comoros 2012 & 100 & -.255 & -.35 & .43 & -.03 & -.17 & 2 & .19 & -.10 & -.23 & 5 & .33 & .06 & .33 & 7 & .36 & .33 & .64 & 85 \\
\hline Congo 2011-12 & 250 & -.173 & -.29 & .38 & .01 & .01 & 0 & .64 & .20 & .36 & 90 & .71 & .03 & .24 & 10 & .30 & -.01 & .02 & 0 \\
\hline $\begin{array}{l}\text { Cote d'Ivoire } \\
2011-12\end{array}$ & 367 & -.122 & -.21 & .30 & -.07 & -.66 & 51 & .37 & -.07 & .16 & 0 & .16 & .06 & .42 & 15 & .37 & .07 & .39 & 34 \\
\hline DRCongo 2013-14 & 711 & -.114 & -.30 & .47 & -.05 & -.28 & 20 & .29 & -.12 & -.55 & 53 & .48 & .10 & .20 & 27 & .31 & .01 & -.26 & 0 \\
\hline Ethiopia 2016 & 419 & -.232 & -.30 & .33 & -.24 & -.57 & 63 & .12 & .09 & .26 & 4 & .10 & -.10 & -.20 & 3 & .38 & .16 & .34 & 30 \\
\hline Gabon 2012 & 209 & -.152 & -.38 & .42 & .03 & .18 & 4 & .87 & -.10 & -.07 & 11 & .66 & -.13 & -.19 & 27 & .24 & .21 & .66 & 58 \\
\hline Gambia 2013 & 251 & -.214 & -.36 & .45 & .04 & .10 & 2 & .51 & -.09 & .15 & 0 & .29 & -.16 & -.19 & 10 & .33 & .34 & .67 & 87 \\
\hline Ghana 2014 & 208 & -.139 & -.22 & .43 & .04 & .36 & 22 & .45 & -.04 & -.09 & 5 & .55 & .09 & .45 & 69 & .35 & .03 & .12 & 4 \\
\hline Guinea 2012 & 298 & -.119 & -.24 & .46 & -.06 & -.39 & 37 & .23 & .08 & -.09 & 0 & .08 & -.05 & -.59 & 9 & .31 & -.11 & -.47 & 54 \\
\hline Kenya 2014 & 609 & -.108 & -.30 & .46 & .02 & .15 & 4 & .41 & .07 & -.06 & 0 & .60 & .07 & .05 & 6 & .36 & -.16 & -.54 & 90 \\
\hline Lesotho 2014 & 135 & -.234 & -.21 & .45 & .00 & .00 & 0 & .18 & -.02 & -.11 & 1 & .70 & -.20 & -.30 & 83 & .26 & .14 & .22 & 16 \\
\hline Liberia 2013 & 276 & -.138 & -.23 & .46 & .03 & .18 & 8 & .49 & .12 & .51 & 84 & .29 & .03 & .34 & 8 & .34 & -.05 & .26 & 0 \\
\hline Malawi 2015-16 & 586 & -.174 & -.25 & .41 & -.12 & -.50 & 54 & .14 & .19 & .70 & 41 & .31 & -.02 & -.09 & 1 & .34 & -.07 & -.05 & 3 \\
\hline Mali 2012-13 & 437 & -.178 & -.22 & .39 & -.06 & -.30 & 18 & .14 & .16 & .45 & 25 & .08 & -.24 & -.92 & 47 & .26 & -.08 & -.18 & 10 \\
\hline Mozambique 2011 & 441 & -.168 & -.26 & .43 & -.11 & -.40 & 41 & .29 & .03 & .41 & 8 & .15 & -.08 & -.01 & 0 & .35 & .12 & .55 & 50 \\
\hline Namibia 2013 & 136 & -.126 & -.30 & .41 & -.07 & -.39 & 30 & .45 & .02 & .27 & 6 & .80 & -.09 & -.11 & 21 & .29 & .09 & .61 & 44 \\
\hline Niger 2012 & 422 & -.142 & -.39 & .44 & -.15 & -.40 & 49 & .10 & -.16 & -.08 & 2 & .04 & -.09 & -.35 & 2 & .29 & .17 & .51 & 46 \\
\hline Nigeria 2013 & 1465 & -.137 & -.21 & .45 & -.08 & -.55 & 72 & .31 & -.06 & -.33 & 21 & .40 & .00 & -.03 & 0 & .29 & -.02 & -.31 & 7 \\
\hline Rwanda 2014-15 & 227 & -.180 & -.38 & .48 & -.22 & -.52 & 81 & .14 & .14 & .47 & 14 & .34 & -.02 & -.11 & 1 & .34 & -.11 & -.07 & 4 \\
\hline Senegal 2010-11 & 476 & -.105 & -.26 & .38 & -.10 & -.60 & 79 & .31 & .07 & .28 & 21 & .11 & .00 & .26 & 0 & .29 & -.03 & .03 & 0 \\
\hline Sierra Leone 2013 & 562 & -.119 & -.24 & .47 & -.08 & -.47 & 63 & .30 & -.03 & -.02 & 1 & .26 & -.07 & -.42 & 27 & .37 & .05 & .14 & 10 \\
\hline Tanzania 2015-16 & 355 & -.238 & -.32 & .44 & -.12 & -.30 & 17 & .36 & .33 & .64 & 82 & .74 & -.04 & -.02 & 1 & .42 & -.14 & .27 & 0 \\
\hline Togo 2013-14 & 224 & -.141 & -.21 & .41 & -.06 & -.19 & 12 & .33 & .18 & .37 & 55 & .26 & -.10 & -.51 & 33 & .33 & -.12 & .23 & 0 \\
\hline Uganda 2016 & 574 & -.141 & -.34 & .45 & -.08 & -.30 & 22 & .20 & .09 & .28 & 11 & .44 & -.15 & -.47 & 66 & .37 & .03 & .03 & 1 \\
\hline Zambia 2013-14 & 436 & -.089 & -.29 & .42 & -.02 & -.33 & 9 & .32 & .03 & .40 & 15 & .49 & -.08 & -.25 & 41 & .34 & .07 & .38 & 35 \\
\hline Zimbabwe 2015 & 206 & -.234 & -.22 & .46 & -.17 & -.54 & 81 & .29 & -.07 & -.29 & 12 & .84 & -.09 & -.05 & 7 & .28 & .02 & -.27 & 0 \\
\hline
\end{tabular}

G: Gini index; mean(y): mean of the predicted (In) death rates; mean: mean of the dummy variable (coded 0/1), corresponds to the proportion of the factor in the country; b: regression coefficient from a multivariate Poisson model (in bold if significant); \%Gini: relative factor's contribution calculated with the regression-based decomposition of the Gini index ; A few negative contributions were restricted to 0 
Table 4 Post-neonatal mortality (1-11 months)

\begin{tabular}{|c|c|c|c|c|c|c|c|c|c|c|c|c|c|c|c|c|c|c|c|}
\hline & \multirow[b]{3}{*}{$\mathrm{n}$} & \multirow[b]{3}{*}{ G } & \multirow[b]{3}{*}{ mean(y) } & \multicolumn{4}{|c|}{ Sex of the child } & \multicolumn{4}{|c|}{ Place of residence } & \multicolumn{4}{|c|}{ Mother's education } & \multicolumn{4}{|c|}{ Household wealth } \\
\hline & & & & \multicolumn{4}{|c|}{ Female } & \multicolumn{4}{|c|}{ Urban } & \multicolumn{4}{|c|}{ Primary+ } & \multicolumn{4}{|l|}{ Richest } \\
\hline & & & & mean & $b$ & c & $\%_{\text {Gini }}$ & mean & $b$ & c & $\%_{\text {Gini }}$ & mean & $\mathrm{b}$ & c & $\%_{\text {Gini }}$ & mean & $\mathrm{b}$ & c & $\%_{\text {Gini }}$ \\
\hline Angola 2015-16 & 3069 & -.042 & -4.48 & .50 & -.10 & -.26 & 7 & .59 & -.10 & -.34 & 11 & .39 & -.04 & -.45 & 4 & .33 & -.68 & -.67 & 79 \\
\hline Benin 2011-12 & 2762 & -.050 & -4.5 & .48 & -.27 & -.26 & 14 & .41 & .11 & -.21 & 0 & .18 & -.07 & -.49 & 3 & .34 & -.87 & -.66 & 83 \\
\hline $\begin{array}{l}\text { Burkina Faso } \\
2010\end{array}$ & 3264 & -.036 & -3.87 & .50 & -.05 & -.24 & 4 & .16 & -.07 & -.78 & 6 & .07 & -.36 & -.84 & 16 & .33 & -.47 & -.67 & 74 \\
\hline Burundi 2016-17 & 2684 & -.047 & -4.26 & .48 & -.01 & -.20 & 0 & .10 & .43 & -.43 & 0 & .26 & -.45 & -.63 & 34 & .33 & -.67 & -.66 & 65 \\
\hline Cameroon 2011 & 2603 & -.042 & -4.07 & .49 & -.14 & -.16 & 7 & .43 & -.10 & -.39 & 10 & .47 & -.49 & -.53 & 71 & .33 & -.12 & -.55 & 12 \\
\hline Chad 2014-15 & 3957 & -.033 & -3.77 & .48 & -.14 & -.38 & 20 & .21 & .12 & .07 & 1 & .17 & -.67 & -.83 & 78 & .33 & -.01 & -.11 & 0 \\
\hline Comoros 2012 & 658 & -.093 & -5 & .51 & .20 & .15 & 3 & .27 & -.56 & -.58 & 19 & .35 & -1.60 & -.65 & 78 & .36 & .06 & -.13 & 0 \\
\hline Congo 2011-12 & 2056 & -.022 & -4.59 & .51 & -.29 & -.47 & 68 & .61 & -.21 & -.22 & 28 & .72 & .09 & .01 & 1 & .34 & -.04 & -.29 & 4 \\
\hline $\begin{array}{l}\text { Cote d'Ivoire } \\
2011-12\end{array}$ & 1763 & -.035 & -4.06 & .50 & -.37 & -.39 & 50 & .36 & -.07 & -.36 & 7 & .19 & -.39 & -.76 & 38 & .33 & -.07 & -.37 & 6 \\
\hline $\begin{array}{l}\text { DRCongo 2013- } \\
14\end{array}$ & 4102 & -.025 & -4.04 & .50 & .05 & .14 & 3 & .30 & .26 & -.25 & 0 & .50 & -.17 & -.36 & 24 & .33 & -.43 & -.63 & 73 \\
\hline Ethiopia 2016 & 2120 & -.043 & -4.47 & .51 & -.32 & -.32 & 28 & .12 & -.68 & -.83 & 35 & .12 & -.72 & -.86 & 37 & .35 & .02 & -.08 & 0 \\
\hline Gabon 2012 & 1352 & -.029 & -4.82 & .48 & -.33 & -.37 & 42 & .84 & -.58 & -.16 & 56 & .77 & -.03 & -.12 & 2 & .35 & .03 & .00 & 0 \\
\hline Gambia 2013 & 1826 & -.032 & -4.89 & .52 & -.07 & -.14 & 3 & .46 & .37 & .11 & 12 & .33 & -.59 & -.67 & 85 & .31 & .03 & .05 & 0 \\
\hline Ghana 2014 & 1239 & -.028 & -4.87 & .47 & -.01 & -.13 & 1 & .45 & .28 & .11 & 10 & .59 & -.51 & -.41 & 89 & .32 & .02 & .03 & 0 \\
\hline Guinea 2012 & 1579 & -.063 & -4.01 & .48 & -.11 & -.22 & 4 & .26 & .28 & -.51 & 0 & .14 & -.78 & -.82 & 30 & .32 & -.94 & -.64 & 66 \\
\hline Kenya 2014 & 4028 & -.024 & -4.5 & .50 & -.25 & -.22 & 25 & .35 & .30 & .30 & 29 & .61 & -.29 & -.28 & 46 & .32 & -.02 & -.04 & 0 \\
\hline Lesotho 2014 & 740 & -.051 & -4.29 & .53 & -.42 & -.31 & 32 & .26 & .40 & .49 & 23 & .82 & -.51 & -.11 & 20 & .31 & .40 & .43 & 24 \\
\hline Liberia 2013 & 1712 & -.025 & -4.21 & .47 & .21 & .35 & 32 & .49 & .18 & .01 & 1 & .32 & -.30 & -.62 & 56 & .31 & -.17 & -.25 & 12 \\
\hline Malawi 2015-16 & 3296 & -.018 & -4.62 & .48 & .00 & .16 & 0 & .14 & -.15 & -.82 & 20 & .30 & .02 & -.05 & 0 & .33 & -.30 & -.67 & 80 \\
\hline Mali 2012-13 & 2171 & -.039 & -4.33 & .49 & -.01 & -.21 & 1 & .20 & -.43 & -.79 & 40 & .10 & -.04 & -.74 & 2 & .35 & -.44 & -.65 & 58 \\
\hline $\begin{array}{l}\text { Mozambique } \\
2011\end{array}$ & 2474 & -.031 & -4.03 & .49 & .10 & .20 & 8 & .27 & -.14 & -.63 & 20 & .18 & -.19 & -.74 & 21 & .32 & -.29 & -.67 & 52 \\
\hline Namibia 2013 & 1111 & -.036 & -4.52 & .51 & .26 & .30 & 23 & .45 & -.42 & -.43 & 47 & .78 & -.40 & -.16 & 30 & .29 & .25 & -.14 & 0 \\
\hline Niger 2012 & 2694 & -.024 & -4.14 & .48 & .10 & .37 & 18 & .13 & -.65 & -.87 & 73 & .06 & .20 & .10 & 1 & .33 & -.05 & -.40 & 7 \\
\hline Nigeria 2013 & 6797 & -.046 & -4.07 & .51 & -.14 & -.18 & 7 & .35 & -.06 & -.47 & 5 & .46 & -.44 & -.53 & 58 & .33 & -.27 & -.62 & 30 \\
\hline Rwanda 2014-15 & 1632 & -.047 & -4.93 & .50 & -.28 & -.28 & 16 & .18 & .23 & -.37 & 0 & .36 & -.24 & -.38 & 13 & .35 & -.77 & -.66 & 71 \\
\hline Senegal 2010-11 & 2600 & -.046 & -4.66 & .48 & .27 & .23 & 14 & .37 & -.45 & -.58 & 44 & .11 & -.80 & -.87 & 36 & .32 & -.08 & -.48 & 6 \\
\hline $\begin{array}{l}\text { Sierra Leone } \\
2013\end{array}$ & 2753 & -.019 & -3.5 & .49 & .06 & .21 & 10 & .25 & .00 & -.54 & 0 & .24 & -.26 & -.76 & 70 & .33 & -.08 & -.55 & 20 \\
\hline $\begin{array}{l}\text { Tanzania 2015- } \\
16\end{array}$ & 2038 & -.006 & -4.45 & .49 & -.02 & -.17 & 4 & .27 & .02 & -.29 & 0 & .67 & .07 & .15 & 25 & .32 & -.11 & -.60 & 71 \\
\hline Togo 2013-14 & 1433 & -.032 & -4.35 & .48 & .01 & .17 & 0 & .34 & -.07 & -.52 & 9 & .31 & -.52 & -.69 & 81 & .31 & -.08 & -.56 & 10 \\
\hline Uganda 2016 & 3089 & -.055 & -4.65 & .50 & -.33 & -.26 & 16 & .19 & -.10 & -.28 & 2 & .42 & -.89 & -.58 & 82 & .32 & .22 & -.16 & 0 \\
\hline Zambia 2013-14 & 2621 & -.020 & -4.34 & .48 & -.13 & -.21 & 16 & .35 & .35 & .30 & 42 & .52 & -.19 & -.34 & 40 & .34 & -.19 & -.03 & 2 \\
\hline Zimbabwe 2015 & 1205 & -.024 & -4.3 & .50 & -.08 & -.22 & 9 & .26 & -.24 & -.73 & 44 & .85 & -.18 & -.15 & 22 & .29 & -.13 & -.71 & 25 \\
\hline
\end{tabular}


Table 5 Infant mortality (0-11 months)

\begin{tabular}{|c|c|c|c|c|c|c|c|c|c|c|c|c|c|c|c|c|c|c|c|}
\hline & \multirow[b]{3}{*}{$\mathrm{n}$} & \multirow[b]{3}{*}{ G } & \multirow[b]{3}{*}{ mean $(y)$} & \multicolumn{4}{|c|}{ Sex of the child } & \multicolumn{4}{|c|}{ Place of residence } & \multicolumn{4}{|c|}{ Mother's education } & \multicolumn{4}{|c|}{ Household wealth } \\
\hline & & & & \multicolumn{4}{|c|}{ Female } & \multicolumn{4}{|c|}{ Urban } & \multicolumn{4}{|c|}{ Primary+ } & \multicolumn{4}{|c|}{ Richest } \\
\hline & & & & mean & $b$ & c & $\%_{\text {Gini }}$ & mean & $b$ & c & $\%_{\text {Gini }}$ & mean & $b$ & c & $\%_{\text {Gini }}$ & mean & $b$ & c & $\%_{\text {Gini }}$ \\
\hline Angola 2015-16 & 3514 & -.047 & -3.61 & .49 & -.31 & -.31 & 28 & .58 & -.20 & -.32 & 22 & .38 & -.06 & -.42 & 6 & .32 & -.35 & -.66 & 44 \\
\hline Benin 2011-12 & 3168 & -.033 & -3.61 & .47 & -.21 & -.24 & 19 & .41 & .12 & -.20 & 0 & .17 & -.23 & -.75 & 23 & .34 & -.35 & -.63 & 58 \\
\hline Burkina Faso 2010 & 3824 & -.035 & -3.26 & .49 & -.12 & -.27 & 13 & .16 & -.01 & -.69 & 1 & .07 & -.24 & -.84 & 13 & .32 & -.38 & -.68 & 73 \\
\hline Burundi 2016-17 & 3079 & -.027 & -3.51 & .48 & -.08 & -.20 & 9 & .10 & .32 & .18 & 6 & .26 & -.30 & -.69 & 59 & .33 & -.18 & -.42 & 26 \\
\hline Cameroon 2011 & 3037 & -.030 & -3.31 & .49 & -.09 & -.13 & 6 & .42 & -.13 & -.47 & 25 & .46 & -.23 & -.53 & 55 & .32 & -.08 & -.56 & 14 \\
\hline Chad 2014-15 & 4669 & -.031 & -3.11 & .47 & -.20 & -.39 & 37 & .21 & .05 & .08 & 1 & .17 & -.41 & -.83 & 61 & .33 & .02 & .13 & 1 \\
\hline Comoros 2012 & 758 & -.051 & -3.72 & .50 & -.12 & -.19 & 6 & .26 & -.59 & -.72 & 57 & .35 & -.36 & -.49 & 33 & .36 & .32 & .06 & 4 \\
\hline Congo 2011-12 & 2306 & -.037 & -3.75 & .50 & -.45 & -.50 & 81 & .61 & .18 & .08 & 7 & .72 & .04 & .08 & 2 & .33 & -.21 & -.21 & 10 \\
\hline $\begin{array}{l}\text { Cote d'Ivoire } \\
2011-12\end{array}$ & 2130 & -.059 & -3.22 & .47 & -.64 & -.54 & 85 & .36 & -.09 & -.01 & 0 & .18 & -.26 & -.45 & 11 & .34 & .16 & .13 & 4 \\
\hline DRCongo 2013-14 & 4813 & -.018 & -3.34 & .50 & -.07 & -.25 & 13 & .30 & .08 & -.33 & 0 & .49 & -.02 & -.25 & 3 & .33 & -.26 & -.67 & 84 \\
\hline Ethiopia 2016 & 2539 & -.062 & -3.48 & .48 & -.71 & -.52 & 83 & .12 & -.18 & -.12 & 1 & .11 & -.46 & -.43 & 11 & .35 & .21 & .16 & 6 \\
\hline Gabon 2012 & 1561 & -.041 & -3.75 & .47 & -.26 & -.36 & 30 & .84 & .03 & -.02 & 0 & .75 & -.45 & -.24 & 52 & .33 & -.23 & -.36 & 18 \\
\hline Gambia 2013 & 2077 & -.036 & -3.83 & .51 & -.15 & -.20 & 11 & .46 & .30 & .36 & 37 & .32 & -.43 & -.33 & 33 & .31 & .18 & .44 & 18 \\
\hline Ghana 2014 & 1447 & -.022 & -3.62 & .47 & -.08 & -.29 & 13 & .45 & -.06 & .04 & 0 & .59 & -.28 & -.32 & 64 & .32 & .27 & .22 & 23 \\
\hline Guinea 2012 & 1877 & -.047 & -3.23 & .47 & -.10 & -.24 & 7 & .26 & .02 & -.53 & 0 & .13 & -.60 & -.87 & 43 & .32 & -.38 & -.62 & 49 \\
\hline Kenya 2014 & 4637 & -.025 & -3.62 & .49 & -.21 & -.32 & 36 & .36 & .29 & .50 & 55 & .61 & -.17 & -.08 & 9 & .33 & -.05 & .17 & 0 \\
\hline Lesotho 2014 & 875 & -.055 & -3.38 & .52 & -.39 & -.34 & 37 & .25 & -.04 & -.05 & 0 & .80 & -.71 & -.18 & 55 & .30 & .33 & .15 & 8 \\
\hline Liberia 2013 & 1988 & -.019 & -3.47 & .47 & .12 & .30 & 25 & .49 & .11 & .09 & 7 & .32 & -.23 & -.60 & 65 & .31 & .07 & .09 & 3 \\
\hline Malawi 2015-16 & 3882 & -.018 & -3.54 & .47 & -.22 & -.53 & 83 & .14 & .12 & .43 & 11 & .30 & -.01 & -.11 & 0 & .33 & -.11 & -.12 & 6 \\
\hline Mali 2012-13 & 2608 & -.047 & -3.33 & .48 & -.29 & -.29 & 26 & .19 & -.08 & -.70 & 7 & .10 & -.16 & -.62 & 6 & .33 & -.44 & -.66 & 61 \\
\hline Mozambique 2011 & 2915 & -.020 & -3.3 & .48 & -.14 & -.37 & 37 & .28 & .00 & -.22 & 0 & .17 & -.29 & -.83 & 63 & .33 & .02 & -.07 & 0 \\
\hline Namibia 2013 & 1247 & -.020 & -3.73 & .50 & -.11 & -.22 & 16 & .45 & -.20 & -.38 & 44 & .78 & -.21 & -.18 & 40 & .29 & .16 & -.03 & 0 \\
\hline Niger 2012 & 3116 & -.022 & -3.46 & .48 & -.08 & -.42 & 22 & .12 & -.52 & -.88 & 74 & .06 & -.07 & -.62 & 3 & .32 & .02 & -.07 & 0 \\
\hline Nigeria 2013 & 8262 & -.044 & -3.2 & .50 & -.24 & -.22 & 19 & .34 & -.14 & -.50 & 17 & .45 & -.30 & -.53 & 51 & .32 & -.10 & -.58 & 14 \\
\hline Rwanda 2014-15 & 1859 & -.032 & -3.9 & .50 & -.32 & -.40 & 52 & .17 & .02 & -.29 & 0 & .36 & -.15 & -.40 & 17 & .34 & -.23 & -.49 & 31 \\
\hline Senegal 2010-11 & 3076 & -.031 & -3.54 & .47 & -.19 & -.31 & 25 & .36 & -.28 & -.64 & 58 & .11 & -.10 & -.51 & 5 & .31 & -.08 & -.50 & 12 \\
\hline Sierra Leone 2013 & 3315 & -.015 & -2.93 & .49 & -.03 & -.15 & 4 & .26 & .07 & .19 & 7 & .25 & -.20 & -.75 & 84 & .34 & .03 & .20 & 4 \\
\hline Tanzania 2015-16 & 2393 & -.034 & -3.53 & .48 & -.20 & -.33 & 27 & .28 & .36 & .72 & 60 & .68 & .11 & .14 & 9 & .34 & .03 & .50 & 4 \\
\hline Togo 2013-14 & 1657 & -.033 & -3.47 & .47 & -.16 & -.30 & 19 & .34 & -.14 & -.07 & 3 & .31 & -.43 & -.69 & 78 & .32 & .20 & -.03 & 0 \\
\hline Uganda 2016 & 3663 & -.039 & -3.58 & .49 & -.31 & -.37 & 41 & .19 & -.04 & -.15 & 1 & .42 & -.42 & -.45 & 57 & .33 & .26 & .02 & 1 \\
\hline Zambia 2013-14 & 3057 & -.021 & -3.51 & .47 & -.22 & -.53 & 73 & .34 & .00 & .02 & 0 & .51 & -.15 & -.26 & 27 & .34 & .06 & .00 & 0 \\
\hline Zimbabwe 2015 & 1411 & -.024 & -3.36 & .49 & -.19 & -.43 & 36 & .27 & .35 & -.34 & 0 & .85 & -.14 & -.09 & 10 & .29 & -.43 & -.49 & 54 \\
\hline
\end{tabular}

G: Gini index; mean(y): mean of the predicted (In) death rates; mean: mean of the dummy variable (coded 0/1), corresponds to the proportion of the factor in the country; b: regression coefficient from a multivariate Poisson model (in bold if significant); $\%_{\text {Gini: }}$ relative factor's contribution calculated with the regression-based decomposition of the Gini index ; A few negative contributions were restricted to 0 


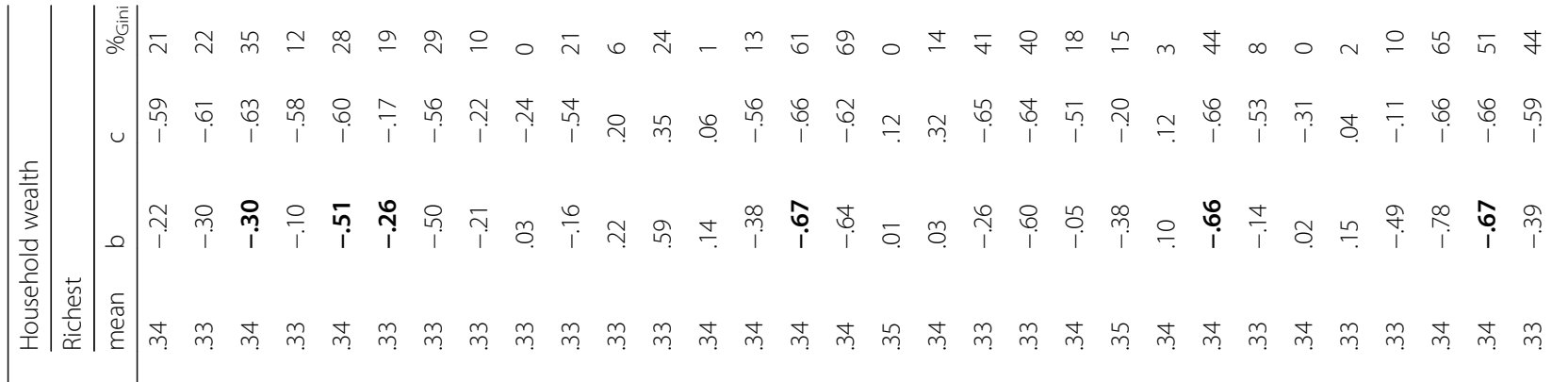

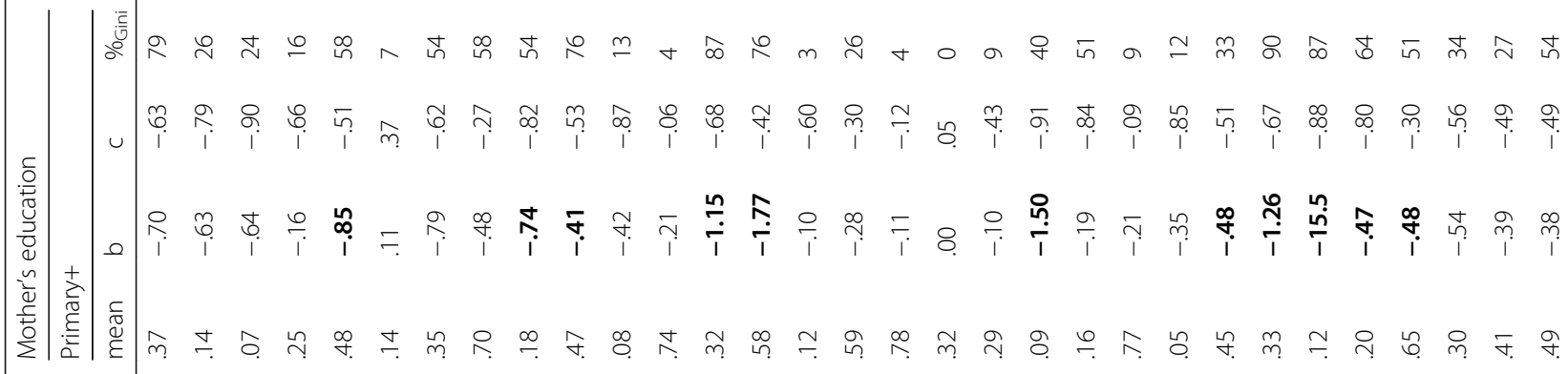

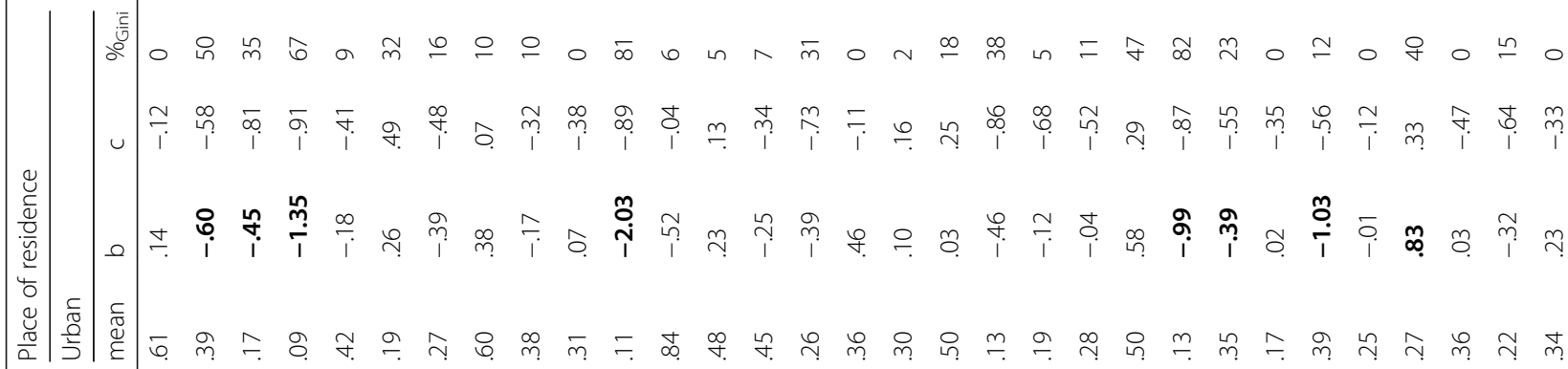

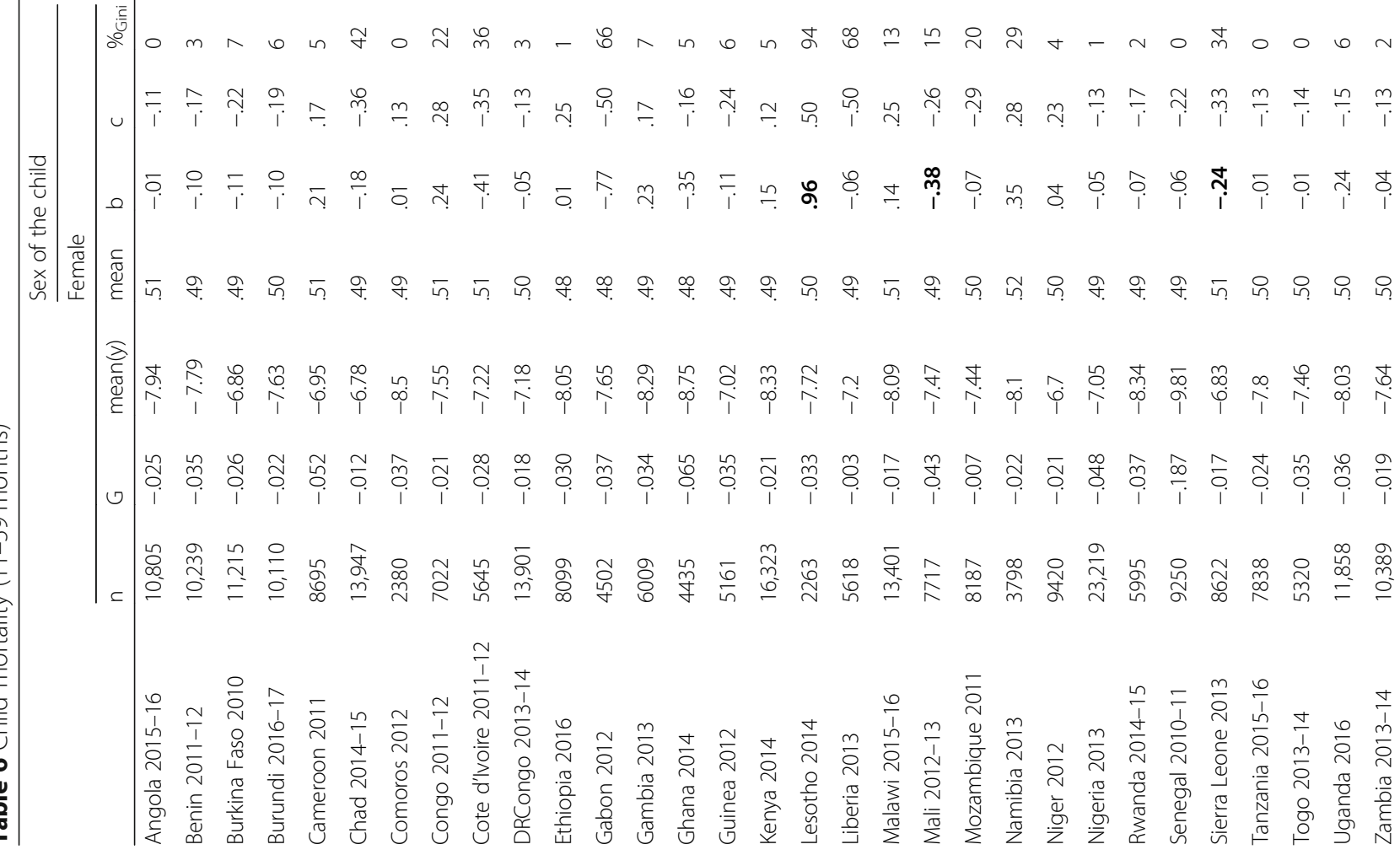




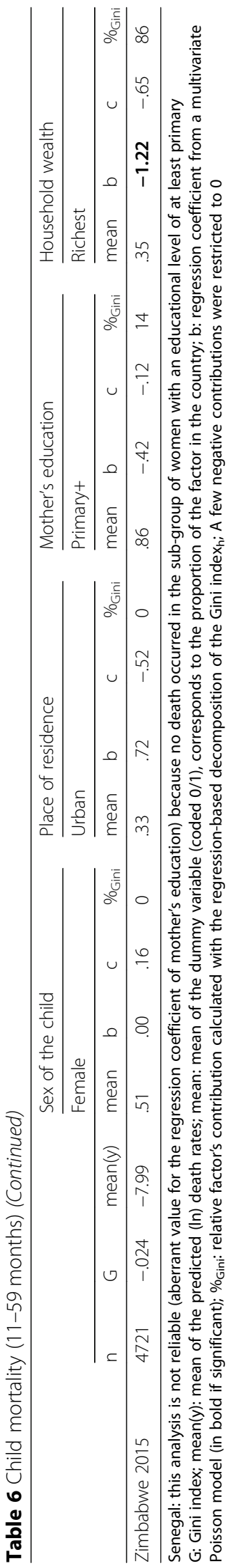




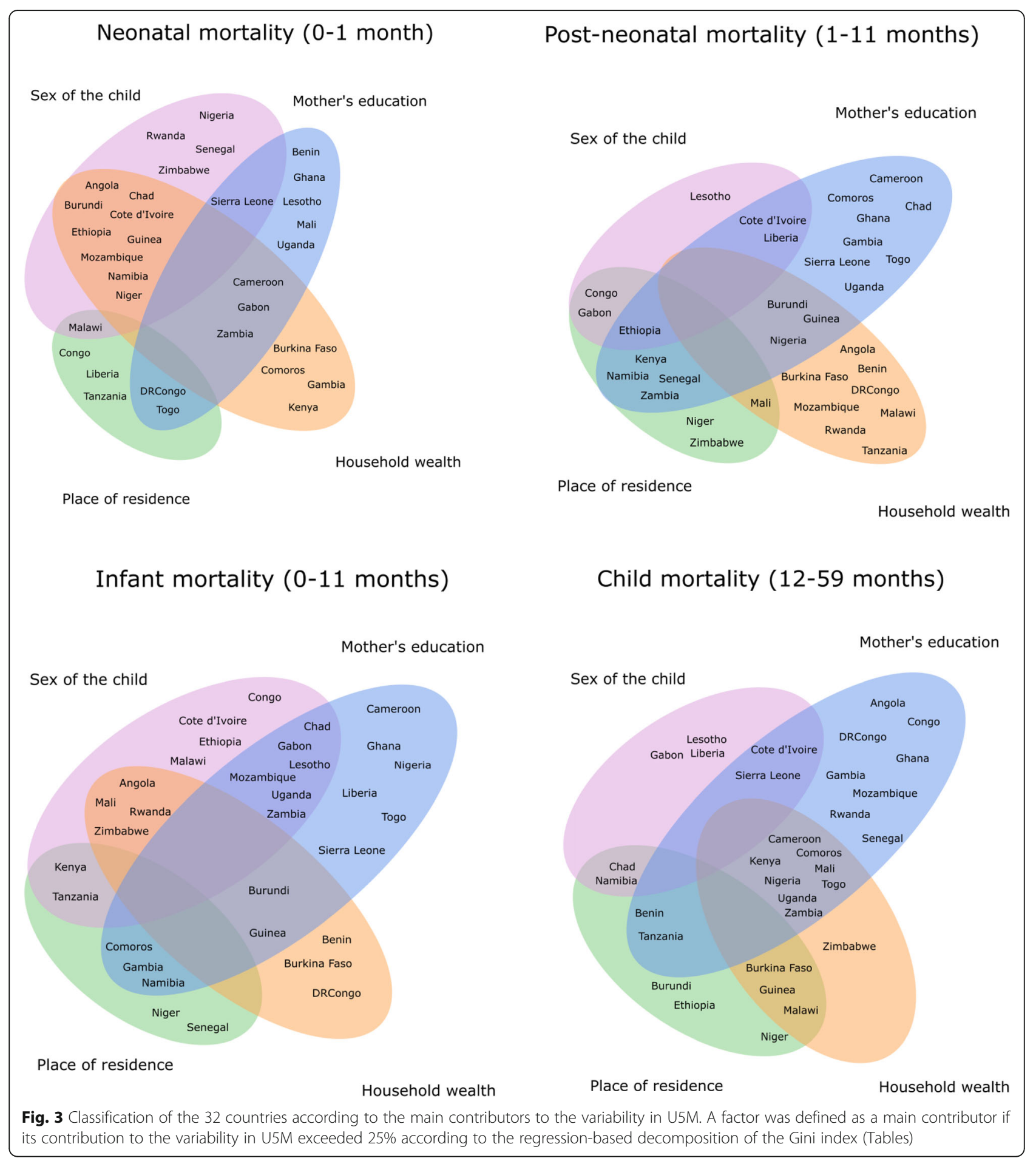




\section{Abbreviations}

DHS: Demographic and Health Survey; DR Congo: the Democratic Republic of the Congo; SDG3: The third Sustainable Development Goal; U5MR: Underfive mortality rate

\section{Acknowledgments}

We thank the Measure Demographic and Health Survey Program for the datasets. We are grateful to Cesar Victora (International Center for Equity in Health, Pelotas, Brazil) for reviewing the original draft of the paper and for raising awareness about the hierarchical relations between determinants. We are also grateful to the reviewers for their comments and suggestions.

\section{Authors' contributions}

$\mathrm{CVM}, \mathrm{AA}, \mathrm{AB}, \mathrm{BM}, \mathrm{HVO}$ and NS contributed to the conceptualization and methodology; CVM and BM contributed to the formal analysis; CVM contributed to the original draft; NS and HVO contributed to the supervision, and all authors contributed to the writing - review and editing of the final manuscript. All authors have read and approved the manuscript.

\section{Funding}

The work received no specific funding.

\section{Availability of data and materials}

The data that support the findings of this study are available from the Measure DHS program (https:/dhsprogram.com/) but restrictions apply to the availability of these data, which were used under license for the current study, and so are not publicly available. Data are however available from the authors upon reasonable request and with permission of the Measure DHS program.

\section{Ethics approval and consent to participate}

The study was based on publicly available data from the DHS program (permission was granted to download data). Ethical approval was the responsibility of the institutions which collected the data.

\section{Consent for publication}

Not Applicable.

\section{Competing interests}

The authors declare that they have no competing interests.

\section{Author details}

'Institute of Health and Society (IRSS), Université catholique de Louvain, Brussels, Belgium. 2Johns Hopkins Bloomberg School of Public Health, $615 \mathrm{~N}$. Wolfe St, Baltimore, MD 21205, USA. ${ }^{3}$ Universidade Federal de Pelotas, Pelotas, Brazil. ${ }^{4}$ Centre de Recherche en Démographie, Université catholique de Louvain, Louvain-la-Neuve, Belgium. ${ }^{5}$ nstitut National d'Etudes Démographiques (INED), Paris, France. ${ }^{6}$ Department of Public Health and Surveillance, Sciensano, Brussels, Belgium. 'Department of Public Health, Ghent University, Ghent, Belgium.

Received: 12 October 2018 Accepted: 5 June 2019

Published online: 14 June 2019

\section{References}

1. UNICEF. The under-five mortality rate: The indispensable gauge of child health. 2016. www.unicef.org/sowc08/docs/sowc08_panels.pdf. Accessed Mar 2016

2. Black RE, Levin C, Walker N, Chou D, Liu L, Temmerman M. Reproductive, maternal, newborn, and child health: key messages from disease control priorities 3rd edition. Lancet. 2016;388(10061):2811-24.

3. United Nations. Sustainable Development Goals. 2016. http://www.un.org/ sustainabledevelopment/health/. Accessed Mar 2016.

4. UN Inter-agency Group for Child Mortality Estimation. Levels \& Trends in child mortality. Report 2018. United nations Children's fund 2018.

5. Liu L, Oza S, Hogan D, Chu Y, Perin J, Zhu J, et al. Global, regional, and national causes of under-5 mortality in 2000-15: an updated systematic analysis with implications for the sustainable development goals. Lancet. 2016;388(10063):3027-35.

6. Tabutin D, Masquelier B. Mortality inequalities and trends in low-and middle-income countries, 1990-2015. Population. 2017;72(2):221-96.
7. World Health Organization. A conceptual framework for action on the social determinants of health. Social Determinants of Health Discussion Paper 22010

8. Gwatkin DR, Rutstein S, Johnson K, Suliman E, Wagstaff A, Amouzou A. Socio-economic differences in health, nutrition, and population within developing countries. Country reports on HNP and poverty; 2007.

9. Gwatkin DR. Reducing health inequalities in developping countries. In: Oxford Textbook of Public Health. 4th ed; 2002.

10. Chao F, You D, Pedersen J, Hug L, Alkema L. National and regional under-5 mortality rate by economic status for low-income and middle-income countries: a systematic assessment. Lancet Glob Health. 2018;6(5):e535-47.

11. Van Malderen C, Van Oyen H, Speybroeck N. Contributing determinants of overall and wealth-related inequality in under-5 mortality in 13 African countries. J Epidemiol Community Health. 2013;67:667-76.

12. Fields GS. Regression-based decompositions: a new tool for managerial decision-making. Ithaca: Working paper, Department of Labor Economics, Cornell University; 2004.

13. Mosley WH, Chen LC. An analytical framework for the study of child survival in developing countries. 1984. Bull World Health Organ. 2003;81(2):140-5.

14. Alkema L, Chao F, You D, Pedersen J, Sawyer CC. National, regional, and global sex ratios of infant, child, and under-5 mortality and identification of countries with outlying ratios: a systematic assessment. Lancet Global Health. 2014;2(9):e521-30.

15. World Health Organization. State of inequality. Reproductive, maternal, newborn and child health. Geneva: World Health Organization; 2015.

16. Measure DHS. The demographic and health surveys program. 2013. Macro International http://www measuredhs.com. Accessed 26 Feb 2013.

17. Direct estimation of child mortality from birth histories. Tools for Demographic Estimation 2013. <http://demographicestimation.iussp.org/content/directestimation-child-mortality-birth-histories $>$. Accessed 22 Apr 2016).

18. Balia S, Jones AM. Mortality, lifestyle and socio-economic status. J Health Econ. 2008 Jan;27(1):1-26.

19. Wagstaff A, van Doorslaer E, Watanabe N. On decomposing the causes of health sector inequalities with an application to malnutrition inequalities in Vietnam. J Econ. 2003;112(1):207-23.

20. Wagstaff A, van Doorslaer E. Overall versus socioeconomic health inequality: a measurement framework and two empirical illustrations. Health Econ. 2004;13(3):297-301.

21. van Doorslaer $\mathrm{E}$, Jones $\mathrm{AM}$. Inequalities in self-reported health: validation of a new approach to measurement. J Health Econ. 2003;22(1):61-87.

22. Drevenstedt GL, Crimmins EM, Vasunilashorn S, Finch CE. The rise and fall of excess male infant mortality. Proc Natl Acad Sci U S A. 2008;105(13):5016-21.

23. Yaya S, Diarra S, Mabeu MC, Pongou R. The sex gap in neonatal mortality and the AIDS epidemic in sub-Saharan Africa. BMJ Glob Health. 2018;3(5):1-5.

24. Boco AG. Assessing sex differentials in under-five mortality in sub-Saharan Africa: a cross-national comparative analysis. Can Stud Popul. 2015;41(3-4):49-87

25. Kanmiki EW, Bawah AA, Agorinya I, Achana FS, Awoonor-Williams JK, Oduro $A R$, et al. Socio-economic and demographic determinants of under-five mortality in rural northern Ghana. BMC Int Health Hum Rights. 2014;14:24

26. Kimani-Murage EW, Fotso JC, Egondi T, Abuya B, Elungata P, Ziraba AK, Kabiru CW, Madise N. Trends in childhood mortality in Kenya: The urban advantage has seemingly been wiped out. Health Place. 2014;29:95-103.

27. Günther I, Harttgen K. Deadly cities? Spatial inequalities in mortality in subsaharan africa. Popul Dev Rev. 2012;38(3):469-86.

28. Bocquier P, Madise NJ, Zulu EM. Is There an Urban Advantage in Child Survival in Sub-Saharan Africa? Evidence From 18 Countries in the 1990s. Demography. 2011;48(2):531-58.

29. Van de Poel $\mathrm{E}, \mathrm{O}$ 'Donnell $\mathrm{O}$, van DE. What explains the rural-urban gap in infant mortality: household or community characteristics? Demography. 2009;46(4):827-50.

30. Aheto JMK. Predictive model and determinants of under-five child mortality: evidence from the 2014 Ghana demographic and health survey. BMC Public Health. 2019;19(1):64.

31. Oyekale AS, Maselwa TC. Maternal education, fertility, and child survival in Comoros. Int J Environ Res Public Health. 2018;15(12):1-17.

32. Tayie FA, Lartey A. Antenatal care and pregnancy outcome in Ghana, the importance of women's education. Afr J Food Agric Nutr Dev. 2008;8(3):291-303

33. Asamoah BO, Agardh A, Pettersson KO, Ostergren PO. Magnitude and trends of inequalities in antenatal care and delivery under skilled care among different socio-demographic groups in Ghana from 1998-2008. BMC Pregnancy and Childbirth. 2014;14:295. 
34. Gyimah SO. A cohort analysis of the timing of first birth and fertility in Ghana. Popul Res Policy Rev. 2003;22(3):251-66.

35. Tsala Dimbuene Z, Amo-Adjei J, Amugsi D, Mumah J, Izugbara C, Beguy D. Women's education and utilization of maternal health services in Africa: a multicountry and socioeconomic stratus analysis. J Biosoc Sci. 2018;50(6):725-48.

36. Bado AR, Susuman AS. *Women's Education and Health Inequalities in Under-Five Mortality in Selected Sub-Saharan African Countries, 1990-2015. PLoS One. 2016;11(7):e0159186.

37. Moser KA, Leon DA, Gwatkin DR. How does progress towards the child mortality millennium development goal affect inequalities between the poorest and least poor? Analysis of demographic and health survey data. BMJ. 2005;331(7526):1180-2.

38. Bendavid E. Changes in child mortality over time across the wealth gradient in less-developed countries. Pediatrics. 2014;134(6):e1551-9.

39. Braveman P. Monitoring equity in health: a policy-oriented approach in low - and middle-income countries. Geneva: World Health Organization; 1998.

40. Masquelier B, Hug L, Sharrow D, You D, Hogan D, Hill K, Liu J, Pedersen J, Alkema L. Global, regional, and national mortality trends in older children and young adolescents (5-14 years) from 1990 to 2016: an analysis of empirical data. Lancet Glob Health. 2018;6(10):e1087-99.

41. Boerma T, Sommerfelt AE. Demographic and health surveys (DHS): contributions and limitations. App Trimest Statist Sanit Mond. 1993:46(4): 222-6.

42. Fabic M, Choi Y, Bird S. A systematic review of demographic and health surveys: data availability and utilization for research. Bull World Health Organ. 2012;90(8):604-12. https://doi.org/10.2471/BLT.11.095513.

43. Alkema L, You D. Child mortality estimation: a comparison of UN IGME and IHME estimates of levels and trends in under-five mortality rates and deaths. PLOS Med. 2012;9(8):e1001288.

44. Victora CG, Huttly SR, Fuchs SC, Olinto MT. The role of conceptual frameworks in epidemiological analysis: a hierarchical approach. Int J Epidemiol. 1997;26(1):224-7.

45. Wagner Z, Heft-Neal S, Bhutta ZA, Black RE, Burke M, Bendavid E. Armed conflict and child mortality in Africa: a geospatial analysis. Lancet. 2018; 392(10150):857-65.

46. The World Bank group. World Bank open data: Battle-related deaths. 2019 https://data.worldbank.org/indicator/NC.BTL.DETH. Accessed 25 Apr 2019

47. Spinakis AAGPVSKPSYJ. Expert review and proposal for measurement of health inequalities in the European Union- summary report. European Commission Directorate general for health and consumers Luxembourg; 2011.

48. Nusselder WJ, Looman CW. Decomposition tools: technical report on attribution tool, European Health Expectancy Monitoring Unit (EHEMU). 2010. http://www.eurohex.eu/pdf/Reports_2010/2010TR7.1_Decomposition\%20tools. pdf. Accessed Sept 2017.

49. Yokota RT, de Moura L, Andrade SS, de Sa NN, Nusselder WJ, Van Oyen H. Contribution of chronic conditions to gender disparities in disability in the older population in Brazil, 2013. Int J Public Health. 2016;61(9):1003-12.

50. Amouzou A, Hill K. Child mortality and socioeconomic status in sub-Saharan Africa. Afr Popul Stud. 2004;19:1

51. Speybroeck N. Classification and regression trees. Int J Public Health. 2012; 57(1):243-6.

52. Strobl C, Boulesteix AL, Kneib T, Augustin T, Zeileis A. Conditional variable importance for random forests. BMC Bioinformatics. 2008;9:307.

\section{Publisher's Note}

Springer Nature remains neutral with regard to jurisdictional claims in published maps and institutional affiliations.

Ready to submit your research? Choose BMC and benefit from:

- fast, convenient online submission

- thorough peer review by experienced researchers in your field

- rapid publication on acceptance

- support for research data, including large and complex data types

- gold Open Access which fosters wider collaboration and increased citations

- maximum visibility for your research: over 100M website views per year

At BMC, research is always in progress.

Learn more biomedcentral.com/submissions 